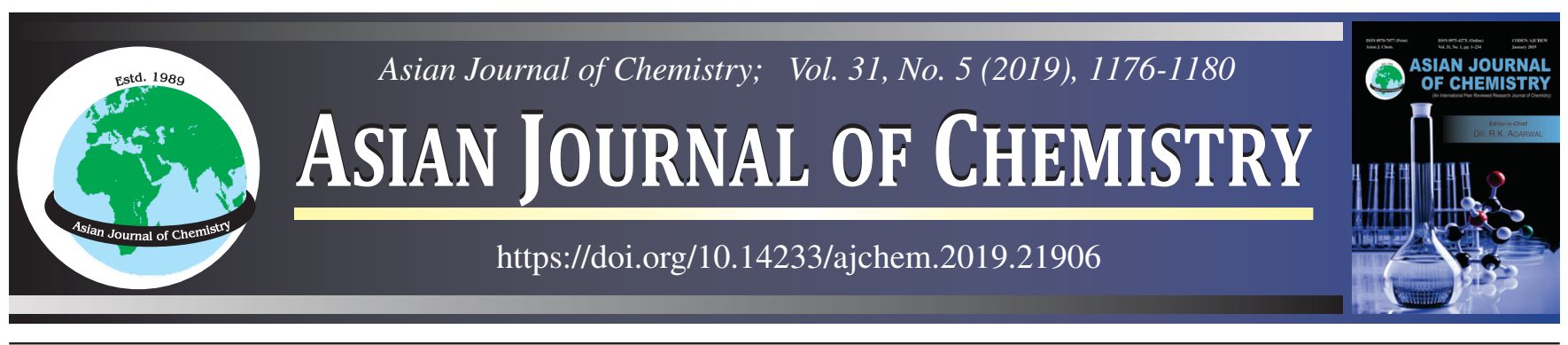

\title{
Synthesis and Characterization of Active Carbon-Titanium Dioxide Composite
}

\author{
Farah S. DaABool ${ }^{1}$ and Falah H. Hussein ${ }^{2,3, *, \bullet}$
}

${ }^{1}$ Continuous Education Center, Al-Qasim Green University, Hilla, Iraq

${ }^{2}$ College of Pharmacy, Babylon University, Hilla, Iraq

${ }^{3}$ Research and Studies Unit, Al-Mustaqbal University College, Hilla, Iraq

*Corresponding author: E-mail: abohasan_hilla@yahoo.com

Received: 30 December 2018;

Accepted: 5 February 2019;

Published online: 28 March 2019;

AJC-19351

Activated carbon was synthesized from Iraqi date palm seeds by physical and chemical activation technique under optimized growth conditions that allow the production of long, well aligned, high-quality activated carbon. Titanium dioxide nanoparticles were prepared using a sol gel method. The activated carbon/ $/ \mathrm{TiO}_{2}$ composites were prepared using simple evaporation and a drying process. The structural, morphological and chemical properties of the prepared activated carbon, $\mathrm{TiO}_{2}$ and activated carbon/ $/ \mathrm{TiO}_{2}$ composite were investigated by $\mathrm{X}$-ray diffraction, Fourier transformed infrared and scanning electron microscope. The photocatalytic activity of activated carbon/TiO ${ }_{2}$ composite with $10 \%$ of activated carbon was studied and compared with $\mathrm{TiO}_{2}$. The UV light photocatalytic activity was also evaluated by the photocatalytic degradation of phenol in an aqueous solution.

| Keywords: Activated Carbon, Titanium dioxide, Composite, Photocatalytic degradation, Phenol.

\section{INTRODUCTION}

One of the main environmental contaminants is wastewater, which is the left-over water after industrial processes. The pollutants in water result from the industry can be related to increasing population and industrial expansion. The most important of these pollutants is phenol, which is becoming a great concern to the environment and public health [1]. Several methods have been used to remove pollutants from wastewaters, including chemical oxidation [2], biodegradation [3], electrocoagulation [4], photodegradation [5], solvent extraction [6], ultra-filtration [7] and adsorption [8].

The adsorption process is best method for wastewater treatment because of its simple design, easy process. Separation occurs because differences in molecular weight, form or polar reason few particles to be held strongly over the surface from others. In many cases, the adsorbate is held strongly enough to allow complete removal of that component of fluid [9-26]. In industry, there are several adsorbent materials are used to purify water. The most recognized such adsorbent is activated carbon, which is the commercial name of a solid, porous, black carbonaceous material with adsorbent properties. Activated carbon consists of a wide network of pores of molecular size within the carbon particles, and non-planar layers of carbon (with some linear or single bonded carbons), which limits the proximity of the adsorbed atoms or molecules. The surface area within the pores of activated carbon is a boundary condition [12-14]. Electron density determines when the pore shape is curved.

The main methods for synthesis of activated carbon are physical and chemical activation. Physical activation consists of two methods i.e., carbonization and activation. Chemical activation methods involve impregnated raw material in chemical agents such as $\mathrm{H}_{3} \mathrm{PO}_{4}, \mathrm{H}_{2} \mathrm{SO}_{4}, \mathrm{KOH}$ or $\mathrm{ZnCl}_{2}$ in an inert atmosphere followed by treatment with moderate or high temperatures $\left(500-800^{\circ} \mathrm{C}\right)$ under a flow of gas with the final temperature being kept for a short period of time under the gas flow and then washed to remove the activating agent.

Many researchers preferentially use low-cost plant and wood-based materials for activated carbon production. Numerous low-cost plants such as palm kernel shell [27], bamboo waste [28] and oil palm shell [29] have been used to produce activated carbon for the removal of textile dye effluents. $\mathrm{TiO}_{2}$ nanoparticles possess different physico-chemical properties have been considered as poorly soluble, low toxicity particles [30]. Velasco et al. [31] reported that $\mathrm{TiO}_{2}$ nanoparticles are manufactured worldwide in large quantities for wide range of applications.

This is an open access journal, and articles are distributed under the terms of the Creative Commons Attribution-NonCommercial-ShareAlike 4.0 (CC BY-NC-SA 4.0) International License which allows readers to freely read, download, copy, distribute, print, search, or link to the full texts of its articles and to use them for any other lawful non-commercial purpose as long as the original source is duly acknowledged. 
Processes used for preparing nano- $\mathrm{TiO}_{2}$ include hydrolysis, drying and calcinations. Various methods have been reported in the literature to prepare nano- $\mathrm{TiO}_{2}$ using $\mathrm{TiCl}_{4}$ [32]. Zhou et al. [30] were synthesized anatase $\mathrm{TiO}_{2}$ nanospindles by hydrothermal method than, fabricated activated carbon/ $/ \mathrm{TiO}_{2}$ composite via a dip-coating method by dispersed $\mathrm{TiO}_{2}$ on the surface of activated carbon. The activated carbon/ $/ \mathrm{TiO}_{2}$ composite has been succeed to remove the organic contaminants in the waste water which exhibits excellent degradation rate in comparison with pure anatase $\mathrm{TiO}_{2}$ nanospindles. Velasco et al. [31] investigated the role of a porous carbon material used as photocatalyst and catalyst support in carbon/titanium composite towards the photodegradation of phenol. The immobilization of titanium on an activated carbon was succeeding in acceleration of the degradation rate under UV irradiation, which attributed to the porosity of the carbon support.

In the present study, activated carbon was prepared from Iraqi date palm seeds which activated by phosphoric acid. $\mathrm{TiO}_{2}$ was prepared from two sources from titanium isopropoxide and $\mathrm{TiCl}_{4}$. The activated carbon/ $/ \mathrm{TiO}_{2}$ composite was prepared by simple evapo-ration and drying process. The composite was characterized by X-ray diffraction and scanning electron microscopy. The activities of synthesized composite were tested with photocatalytic degradation of phenol.

\section{EXPERIMENTAL}

The chemicals phosphoric acid with purity $85 \%$ Merck, ethanol (Sigma-Aldrich), nitric acid (Sigma-Aldrich), sodium hydroxide (BDH), titanium isopropoxide (TIP, Sigma-Aldrich), titanium chloride $\left(\mathrm{TiCl}_{4}\right)(99.99 \%$, Fluka), nitrogen gas (Emirates industrial gases) and phenol within $99.5 \%$ from GCC was used in this study.

Preparation of activated carbon: Khstawy date seeds were used to prepare activated carbon. The seeds were washed with hot distilled water to remove dust and other impurities, dried at $105^{\circ} \mathrm{C}$. Phosphoric acid (30\%) was added to it during the chemical activation process. The activation was completed by heating at temperature $700{ }^{\circ} \mathrm{C}$ for $1 \mathrm{~h}$. After cooling, the activated carbon was washed with distilled water until the $\mathrm{pH}$ of the washing solution reached 6.0-6.5. The product was dried at $105^{\circ} \mathrm{C}$ for $2 \mathrm{~h}$ and kept in tightly closed plastic container. The other activating reagent same procedure for prepared activated carbon.

Preparation of titanium dioxide: $\mathrm{TiO}_{2}$ nanoparticles were prepared using a sol gel method [33]. In brief, $10 \mathrm{~mL}$ of $\mathrm{TiCl}_{4}$ (or $4 \mathrm{~mL}$ of TIP) was added dropwise into $50 \mathrm{~mL}$ of ethanol. The reaction was carried out with a magnetic stirrer under the fume hood in ambient conditions. Afterward, $10 \mathrm{~mL}$ of deionized water was added drop by drop into the resulting solution. The addition of $\mathrm{TiCl}_{4}$ (or TIP) and water were controlled by 10 drops per minute. The product solution was evaporated by drying process at $85{ }^{\circ} \mathrm{C}$ for $4 \mathrm{~h}$ in order to complete digestion. The white suspension was precipitated by aging for 7 days. The white precipitate was then filtered and washed with deionized water three times. Finally, nanopowder of $\mathrm{TiO}_{2}$ was obtained by drying in an oven at $110^{\circ} \mathrm{C}$ for $24 \mathrm{~h} \mathrm{[34-43].}$

Oxidation of activated carbon: Activated carbon $(100 \mathrm{mg})$ was suspended in $50 \mathrm{~mL}$ of $5 \mathrm{~mL}$ of conc. $\mathrm{HNO}_{3}$. The activated carbon suspension was sonicated in a water-bath at room temperature for $1 \mathrm{~h}$ to open the agglomeration of the activated carbon and to anchor the acid solution uniformly on the carbon surface [44].

Preparation of composites: The activated carbon/ $/ \mathrm{TiO}_{2}$ composite was prepared using a simple evaporation and drying process [45]. The commercial titanium dioxide and activated carbon were dispersed into 100 and $20 \mathrm{~mL}$, respectively of distilled water by ultrasonic for $0.5 \mathrm{~h}$. The activated carbon solution was added to $\mathrm{TiO}_{2}$ suspension along with sonication. The suspension containing activated carbon and $\mathrm{TiO}_{2}$ particles was heated to $80^{\circ} \mathrm{C}$ to evaporate the water, then composite was dried overnight in an oven at $100^{\circ} \mathrm{C}$.

Scanning electron microscopy (SEM) analysis were carried out on a JEOL JSM-6700 Finstrument, using a secondary electron detector (SE) at an accelerating voltage of $2.0 \mathrm{kV}$. X-ray diffraction (XRD) were taken to studies the change in composition of titanium dioxide.

The photocatalytic tests were performed at $25^{\circ} \mathrm{C}$ with $1 \mathrm{~g}$ $\mathrm{TiO}_{2}$ and $0.1 \mathrm{~g}$ activated carbon under stirring in $200 \mathrm{~mL}$ of $60 \mathrm{ppm}$ initial concentration of phenol. Samples were maintained in the dark for $1 \mathrm{~h}$ to complete adsorption at equilibrium prior UV irradiation and then the suspension was irradiated. After centrifugation, aliquots were analyzed by UV spectrophotometer Perkin Elmer, Lambda. UV-visible lamp of Metal Halide was used for the photocatalytic tests.

Photocatalytic activity: The photocatalytic activity of activated carbon $/ \mathrm{TiO}_{2}$ composite was determined using phenol decomposition in aqueous solution under an UV lamp (0.7 $\mathrm{mW} / \mathrm{cm}^{2}$ ). The suspensions solutions were prepared by adding $0.175 \mathrm{~g}$ of nanocomposite catalysts to $100 \mathrm{~mL}$ of $60 \mathrm{ppm}$ of phenol aqueous solution. Prior to irradiation, the suspensions were stirred in darkness for $0.5 \mathrm{~h}$ using a magnetic stirrer to ensure adsorption equilibrium. During adsorption and irradiation, the suspensions were sampled at regular intervals. The reaction mixture $(3 \mathrm{~mL})$ was collected and centrifuged for $15 \mathrm{~min}$. The clear solution was carefully removed using a syringe and centrifuged again at the same speed and the same period time. The second centrifuge was found necessary to remove fine particles of the catalyst. After the second centrifuge, the absorbance at the maximum wavelength of $269 \mathrm{~nm}$ of phenol was measured with UV-visible spectrophotometer.

\section{RESULTS AND DISCUSSION}

XRD analysis: The XRD analyses were carried out to examine the structure of synthesized activated carbon. A comparison of both XRDs clearly shows a transformation from an irregular to a regular structure. The peak at $25^{\circ}$ represents the characteristic graphitic peak arising due to the presence of the tubular structure of carbon atoms in sample with (002) planes, the peaks near $44.0^{\circ}$ and $53.2^{\circ}$ are attributed to (101) and (004) planes of structure, respectively [46-50].

Scanning electron microscopy: The SEM micrographs (Fig. 1) of synthesized activated carbon showed the fine growth with some ratio of amorphous carbon.

Catalysts characterization: $\mathrm{The}_{\mathrm{TiO}}$ and activated carbon/ $\mathrm{TiO}_{2}$ composites were characterized using XRD and SEM techniques. 

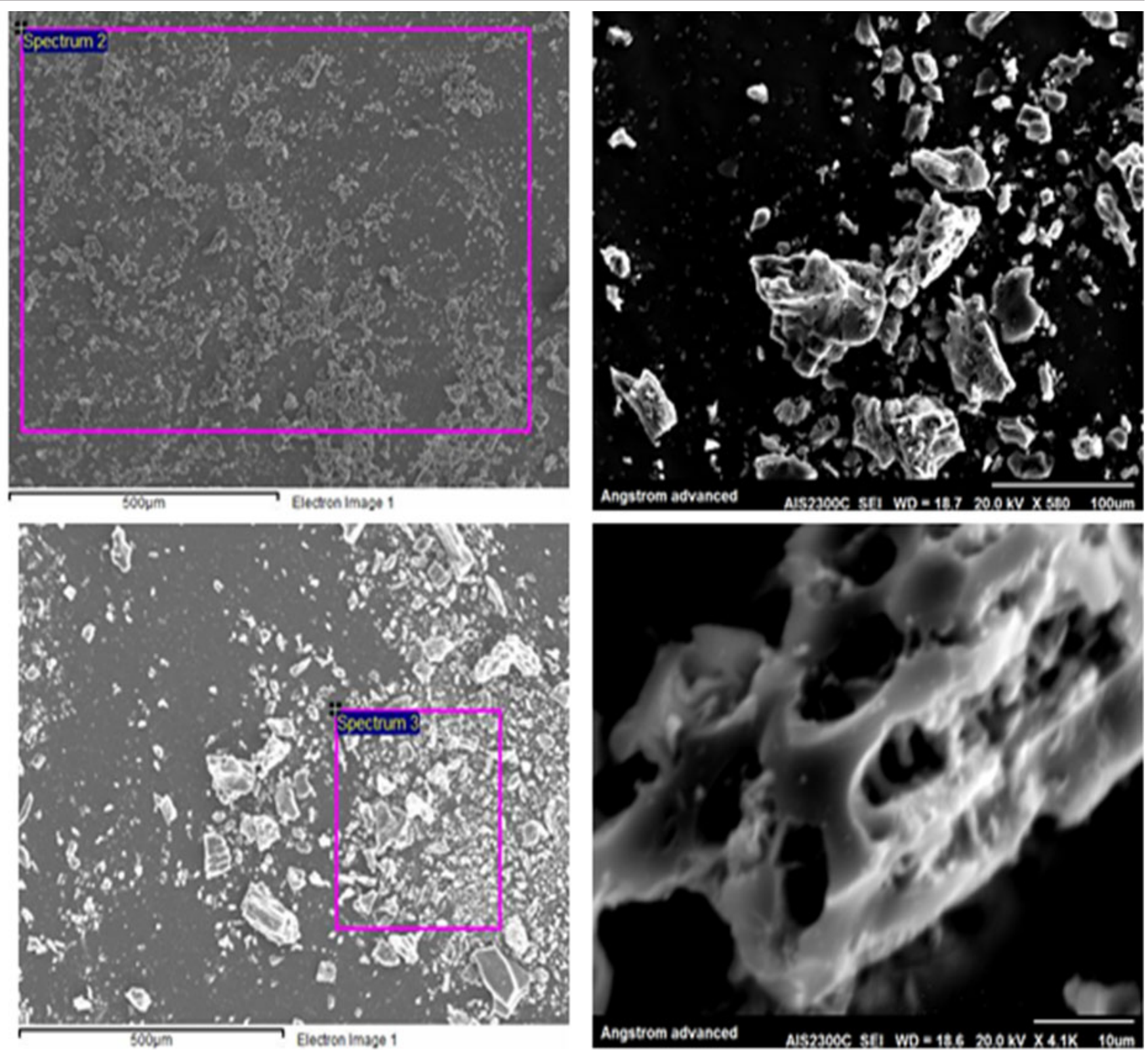

Fig. 1. SEM images of synthesized activated carbon

XRD: The XRD patterns of synthesized $\mathrm{TiO}_{2}$ and activated carbon/ $/ \mathrm{TiO}_{2}$ composites are shown in Figs. 2-4. The average crystallite sizes (D) in nm were calculated using Scherrer's formula.

XRD is used to measure of graphitization. The pattern of activated carbon shows two peak at $2 \theta=25^{\circ}$ and $44^{\circ}$ corresponding to the (002) and (100) reflections, respectively. Fig. 3 showed the XRD patterns of $\mathrm{TiO}_{2}$ compared with activated carbon/TiO 2 composite. The same peaks in $\mathrm{TiO}_{2}$ and composite at $25.3^{\circ}$, $37.8^{\circ}, 48.0^{\circ}, 53.9^{\circ}$ and $62.5^{\circ}$ were the diffractions of (101), (004), (200), (211), and (204) planes of anatase, respectively, and peaks at $27.4^{\circ}, 36.1^{\circ}, 41.2^{\circ}$ and $54.3^{\circ}$ belongs to the diffraction peaks of (110), (101), (111) and (211) planes of rutile, thus indicated that $\mathrm{TiO}_{2}$ and composite contain a mixed structure of anatase and rutile. When comparing the XRD patterns of activated carbon and activated carbon/ $/ \mathrm{TiO}_{2}$ composites, the characteristic peaks for activated carbon at the positions of $25^{\circ}$ and $44^{\circ}$, which become disappearred or become thinner in the XRD pattern of composites. The reason is attributed that

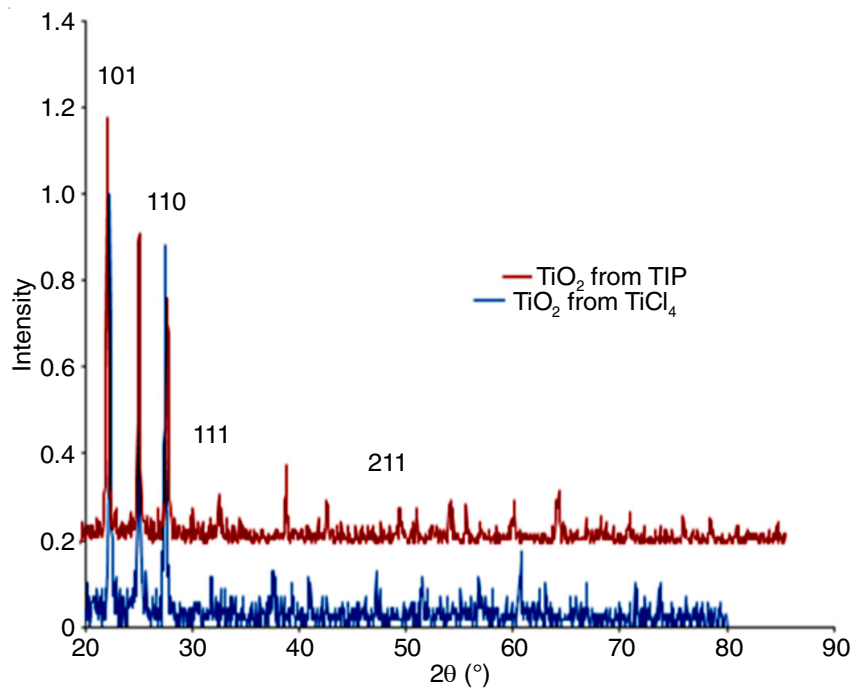

Fig. 2. XRD of synthesized $\mathrm{TiO}_{2}$ 


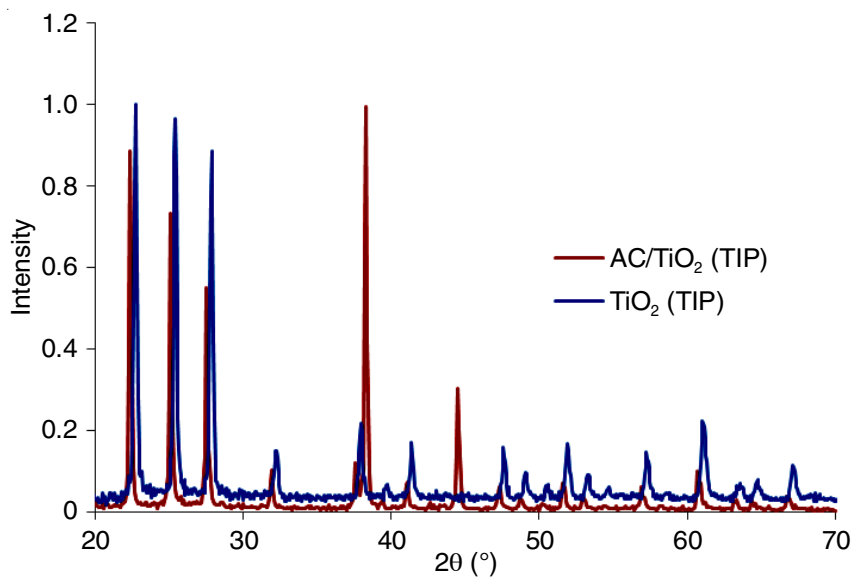

Fig. 3. XRD pattern of activated carbon/ $/ \mathrm{TiO}_{2}$ (TIP) and $\mathrm{TiO}_{2}$ (TIP)

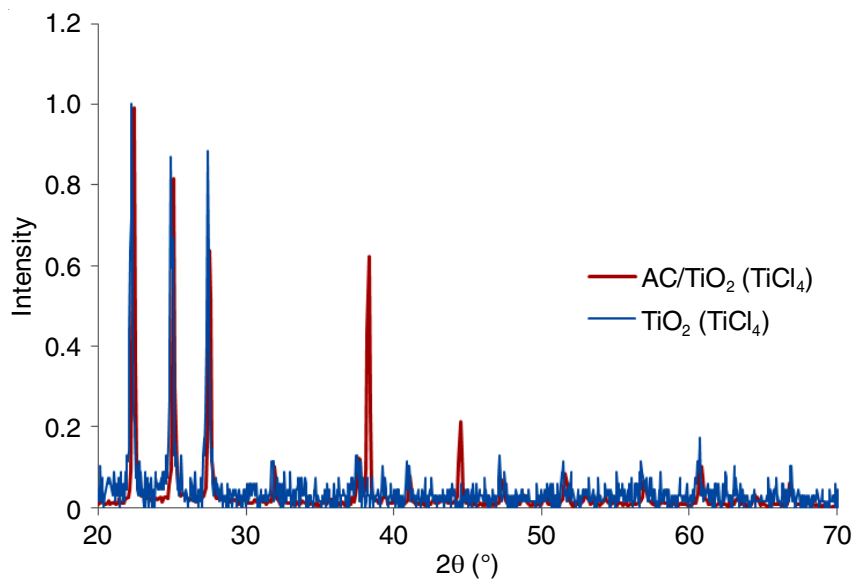

Fig. 4. XRD pattern of activated carbon/ $/ \mathrm{TiO}_{2}\left(\mathrm{TiCl}_{4}\right)$ and $\mathrm{TiO}_{2}\left(\mathrm{TiCl}_{4}\right)$

these peaks in the composites overlapped with the main peak of anatase phase of $\mathrm{TiO}_{2}$ at $25.3^{\circ}$. The average crystallite sizes of $\mathrm{TiO}_{2}$ and activated carbon/ $/ \mathrm{TiO}_{2}$ composite were calculated by Debye-Scherer formula. According to the calculation, the average crystallite sizes of $\mathrm{TiO}_{2}$ and composite activated carbon/ $\mathrm{TiO}_{2}$ were 50 and $58 \mathrm{~nm}$, respectively.

SEM: Figs. 5 and 6 show the SEM images for activated carbon/ $/ \mathrm{TiO}_{2}$ composites synthesized in $\mathrm{TiCl}_{4}$ and TIP, respectively.

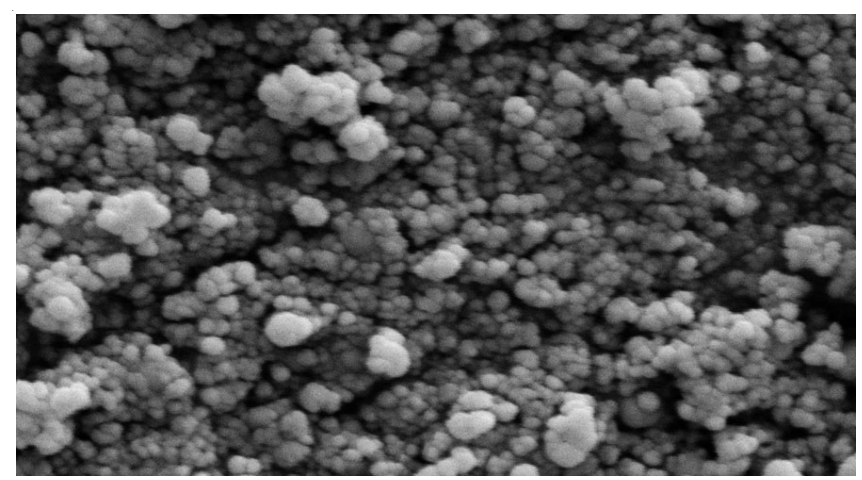

Fig. 5. SEM image of activated carbon $(10 \%) / \mathrm{TiO}_{2}$ (TIP) composite

Photocatalytic activity: The photocatalytic activity of $\mathrm{TiO}_{2}$ and $10 \%$ ratio of activated carbon/ $/ \mathrm{TiO}_{2}$ composites were tested for the photocatalytic photodegredation of phenol in an aqueous solution under UV irradiation. The photocatalytic reactions were carried out in the presence of catalysts and UV

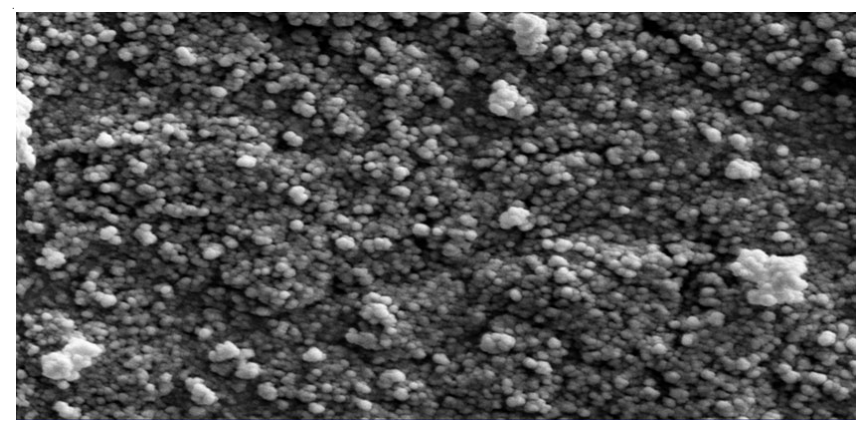

Fig. 6. SEM image of activated carbon $(10 \%) / \mathrm{TiO}_{2}\left(\mathrm{TiCl}_{4}\right)$ composite

(A) light. The photocatalytic activity of all the prepared samples for the photocatalytic photodegredation of phenol was investigated under pre-determined experimental conditions; initial phenol concentration of $60 \mathrm{ppm}$, a light intensity $0.7 \mathrm{~mW} \mathrm{~cm}^{-2}$ at $298.15 \mathrm{~K}$ and pH 6 (Figs. 7-9).

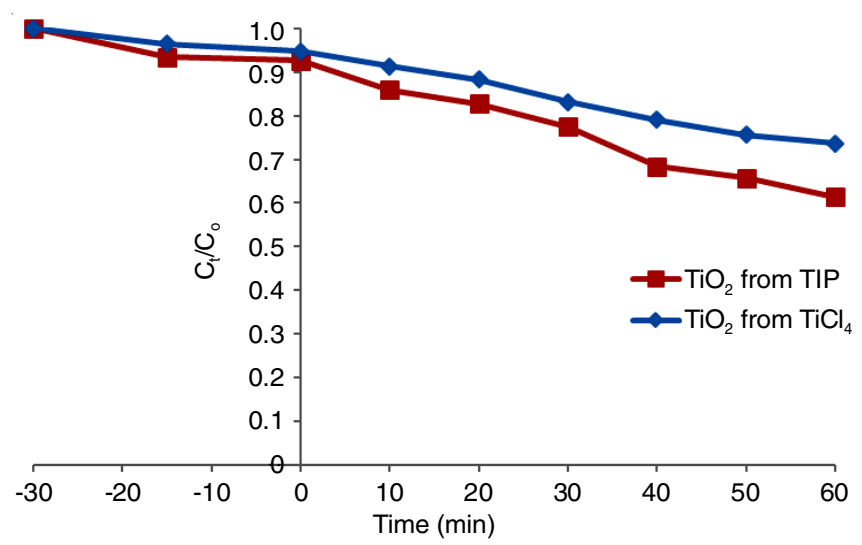

Fig. 7. A dark reaction and light reaction of $\mathrm{TiO}_{2}$ synthesized

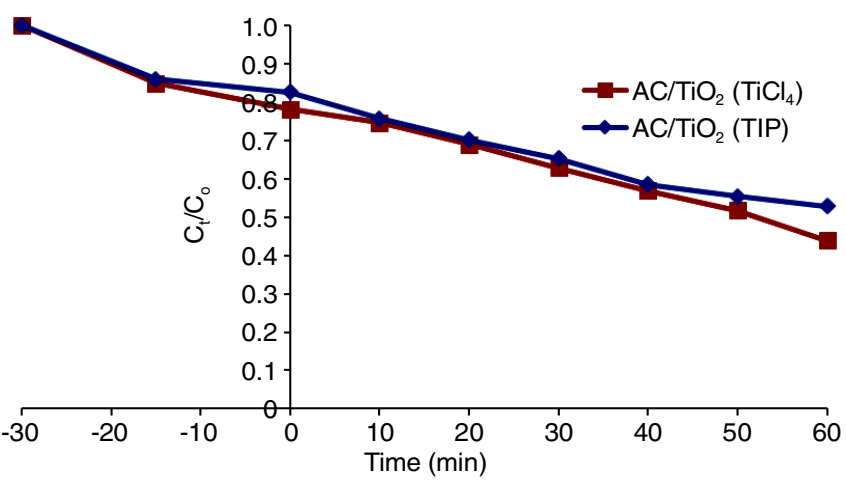

Fig. 8. A dark reaction and irradiation at different activated carbon/ $/ \mathrm{TiO}_{2}$ composites

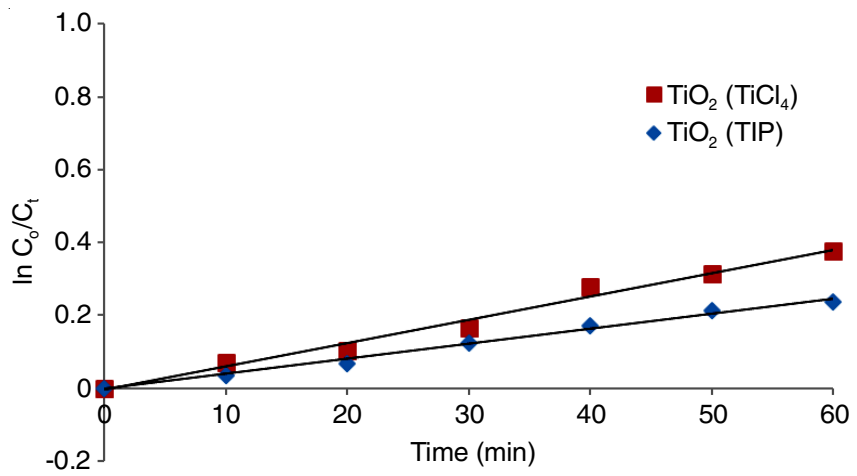

Fig. 9. The changes of $\ln \mathrm{C}_{\mathrm{o}} / \mathrm{C}_{\mathrm{t}}$ according to irradiation times at different $\mathrm{TiO}_{2}$ composites 


\section{Conclusion}

In this work, activated carbon was synthesized from Iraqi date palm seeds. It was found that $\mathrm{TiO}_{2}$ coated by activated carbon exhibits higher photoactivity under UV-visible light irradiation then $\mathrm{TiO}_{2}$ alone. The mechanism of interaction between carbon and organic pollutant is through $\pi$-bonding. The increase its efficiency and selectivity of adsorption is due to the increased surface area. The carbon support affects the nature of phenol degradation mechanism through the formation of different intermediates. Additionally, phenol photodecomposition rate over the carbon/titanium composite, suggested an important self-photoactivity of carbon support.

\section{CONFLICT OF INTEREST}

The authors declare that there is no conflict of interests regarding the publication of this article.

\section{REFERENCES}

1. L.G.C. Villegas, N. Mashhadi, M. Chen, D. Mukherjee, K.E. Taylor and N. Biswas, Curr. Pollution Rep., 2, 157 (2016);

https://doi.org/10.1007/s40726-016-0035-3.

2. M. Bartolomeu, M.G.P.M.S. Neves, M.A.F. Faustino and A. Almeida, Photochem. Photobiol. Sci., 17, 1573 (2018); https://doi.org/10.1039/C8PP00249E.

3. S.A. Ong, E. Toorisaka, M. Hirata and T. Hano, J. Hazard. Mater. B, 124, 88 (2005);

https://doi.org/10.1016/j.jhazmat.2005.03.054.

4. A.K. Golder, N. Hridaya, A.N. Samanta and S. Ray, J. Hazard. Mater., 127, 134 (2005); https://doi.org/10.1016/j.jhazmat.2005.06.032.

5. I. Fatimah, S. Wang and D. Wulandari, Appl. Clay Sci., 53, 553 (2011); https://doi.org/10.1016/j.clay.2011.05.001.

6. G. Muthuraman, T.T. Teng, C.P. Leh and I. Norli, J. Hazard. Mater, 163, 363 (2009); https://doi.org/10.1016/j.jhazmat.2008.06.122.

7. M. Bielska and K. Prochaska, Dyes Pigments, 74, 410 (2007); https://doi.org/10.1016/j.dyepig.2006.03.001.

8. A.M.M. Vargas, A.L. Cazetta, M.H. Kunita, T.L. Silva and V.C. Almeida, Chem. Eng. J., 168, 722 (2011); https://doi.org/10.1016/j.cej.2011.01.067.

9. D.Y. Goswami and D.M. Blake, Mech. Eng., 118, 56 (1996).

10. W.L. McCabe, J.C. Smith and P. Harriot, Unit Operations of Chemical Engineering, McGraw-Hill: Singapore (2005).

11. A. Gundogdu, C. Duran, H.B. Senturk, M. Soylak, D. Ozdes, H. Serencam and M. Imamoglu, J. Chem. Eng. Data, 57, 2733 (2012); https://doi.org/10.1021/je300597u.

12. V. Russo, M. Trifuoggi, M. Di Serio and R, Tesser, Chem. Eng. Technol., 40, 799 (2017); https://doi.org/10.1002/ceat.201600582.

13. F. Rodriguez-Reinoso and A. Linares-Solano, Chemistry and Physics of Carbon, Marcel Dekker, Inc., New York, vol. 21 (1989).

14. C.P.J. Suhas and C.M.M. Ribeiro, Bioresour. Technol., 98, 2301 (2007); https://doi.org/10.1016/j.biortech.2006.08.008.

15. A. Dabrowski, P. Podkoscielny, Z. Hubicki and M. Barczak, Chemosphere, 58, 1049 (2005); https://doi.org/10.1016/j.chemosphere.2004.09.067.

16. S.J. Allen and B. Koumanova, J. Univ. Chem. Technol. Metall., 40, 175 (2005).

17. L.R. Radovic, C. Moreno-Castilla and J. Rivera-Utrilla, ed.: L.R. Radovic, Chemistry and Physics of Carbon, Marcel Dekker: New York, pp. 227405 (2001)

18. G.J. Mcdougall, J.S. Afr. Inst. Min. Metall., 91, 109 (1991).

19. Y. Guo and D.A. Rockstraw, Bioresour. Technol., 98, 1513 (2007); https://doi.org/10.1016/j.biortech.2006.06.027.

20. N.M. Mustapha, M.A.A. Mustajab, A.R Yacob and H.M Al-Swaidan, Journal IEEE Explore, MIM, 511-517 (2010).

21. T. Watari, H. Tsubira, T. Torikai, M. Yada and S. Furuta, J. Ceram. Process. Res., 4, 177 (2003).
22. W. Li, K. Yang, J. Peng, L. Zhang, S. Guo and H. Xia, Ind. Crops Prod., 28, 190 (2008); https://doi.org/10.1016/j.indcrop.2008.02.012.

23. M. Jagtoyen and F. Derbyshire, Carbon, 36, 1085 (1998); https://doi.org/10.1016/S0008-6223(98)00082-7.

24. B.S. Girgis and A.-N.A. El-Hendawy, Micropor. Mesopor. Mater, 52, 105 (2002);

https://doi.org/10.1016/S1387-1811(01)00481-4.

25. N. Muchanyereyi, L. Chiripayi, D. Shasha and M. Mupa, Br. J. Appl. Sci. Technol., 3, 648 (2013); https://doi.org/10.9734/BJAST/2014/3086.

26. G.G. Stavropoulos, P. Samaras and G.P. Sakellaropoulos, J. Hazard. Mater., 151, 414 (2008); https://doi.org/10.1016/j.jhazmat.2007.06.005.

27. T.A. Robertson, W.Y. Sanchez and M.S. Roberts, J. Biomed. Nanotechnol., 6, 452 (2010); https://doi.org/10.1166/jbn.2010.1145.

28. A.D. Abid, D.S. Anderson, G.K. Das, L.S. Van Winkle and I.M. Kennedy, Part. Fibre Toxicol., 10, 1 (2013); https://doi.org/10.1186/1743-8977-10-1.

29. P.K. Chayande, S.P. Singh and M.K.N. Yenkie, Chem. Sci. Transc., 2, 835 (2010); https://doi.org/10.7598/cst2013.358.

30. W. Zhou, P. Zhang and W. Liu, Int. J. Photoenergy, 2012, Article ID 325902 (2012); https://doi.org/10.1155/2012/325902.

31. L.F. Velasco, J.B. Parra and C.O. Ania, Appl. Surf. Sci., 256, 5254 (2010); https://doi.org/10.1016/j.apsusc.2009.12.113.

32. C.R. Girish and V.R. Murty, Int. Res. J. Environ. Sci., 2, 96 (2013).

33. M.Z. Alam, S.A. Muyibi, M.F. Mansor and R. Wahid, J. Environ. Sci., 19, 103 (2007); https://doi.org/10.1016/S1001-0742(07)60017-5.

34. J. Matos, J. Laine and J.-M. Herrmann, J. Catal., 200, 10 (2001); https://doi.org/10.1006/jcat.2001.3191.

35. E.R. Bandala, M.A. Peláez, D.D. Dionysiou, S. Gelover, J. Garcia and D. Macías, J. Photochem. Photobiol. Chem., 186, 357 (2007); https://doi.org/10.1016/j.jphotochem.2006.09.005.

36. W.H. Glaze, J.-W. Kang and D.H. Chapin, Ozone Sci. Eng., 9, 335 (1987); https://doi.org/10.1080/01919518708552148.

37. W.H. Glaze, Environ. Sci. Technol., 21, 224 (1987); https://doi.org/10.1021/es00157a001.

38. M.A. Shaheed and F.H. Hussein, J. Nanomater., 2014, Article ID 198561 (2014); https://doi.org/10.1155/2014/198561.

39. N.B. Chaure, A.K. Ray and R. Capan, Semiconduct. Sci. Technol., 20, 788 (2005); https://doi.org/10.1088/0268-1242/20/8/025.

40. J.X. Xu, L.P. Li, Y.J.Yan, H. Wang, X.X. Wang, X.Z. Fu and G.S. Li, J. Colloid. Interface Sci., 318, 29 (2008); https://doi.org/10.1016/j.jcis.2007.10.004.

41. J. Liqiang, S. Xiaojun, C. Weimin, X. Zili, D. Yaoguo and F. Honggan, J. Phys. Chem. Solids, 64, 615 (2003); https://doi.org/10.1016/S0022-3697(02)00362-1.

42. C.T. Dinh, T.D. Nguyen, F. Kleitz and T.O. Do, ACS Nano, 3, 3737 (2009); https://doi.org/10.1021/nn900940p.

43. D.L. Liao and B.Q. Liao, J. Photochem. Photobiol. Chem., 187, 363 (2007); https://doi.org/10.1016/j.jphotochem.2006.11.003.

44. T. Paxton and L. Thiên-Nga, J. Phys. Rev. B, 57, 1579 (1998); https://doi.org/10.1103/PhysRevB.57.1579.

45. A. Sclafani, L. Palmisano and M. Schiavello, J. Phys. Chem., 94, 829 (1990); https://doi.org/10.1021/j100365a058.

46. T. Torimoto, Y. Okawa, N. Takeda and H. Yoneyama, J. Photochem. Photobiol. Chem., 103, 153 (1997); https://doi.org/10.1016/S1010-6030(96)04503-0.

47. A.W.M. Ip, J.P. Barford and G. McKay, Bioresour. Technol., 99, 8909 (2008); https://doi.org/10.1016/j.biortech.2008.04.076.

48. A.M. García, A.J. Hunt, V.L. Budarin, H.L. Parker, P.S. Shuttleworth, G.J. Ellis and J.H. Clark, Green Chem., 2015, 2146 (2015); https://doi.org/10.1039/C5GC00154D.

49. Z. Al-Qodah and R. Shawabkah, Braz. J. Chem. Eng., 26, 127 (2009); https://doi.org/10.1590/S0104-66322009000100012.

50. Liu and Zhao, BioResources, 7, 5552 (2012). 